\title{
Neonatal Morbidity and Mortality from 2010 to 2016 in the Neonatal Care Unit of the University Teaching Hospital of Parakou/Benin
}

\author{
Alphonse Noudamadjo 1*, Gérard M. Kpanidja1, Falilatou Agbeille Mohamed1, \\ Kolawolé Mavlison Zinvokpodo', Rodrigue Ahodegnon', Joseph Agossou1, \\ Julien Didier Adédémy¹, Blaise Ayivi²
}

${ }^{1}$ Mother \& Child Department, Faculty of Medecine, University Teaching Hospital of Parakou, Parakou, Benin

${ }^{2}$ Mother \& Child Department, Faculty of Health Sciences, University of Abomey-Calavi; and Pediatrics \& Medical Genetic Clinic, Hubert K Maga National University Teaching Hospital (CNHU-HKM) of Cotonou, Cotonou, Benin

Email: *alphonse_ndama@yahoo.fr, m.kpanidjagerard@yahoo.ca,fmagbeille@yahoo.fr, kolawolezinvokpodomakozi@gmail.com,roahodegnon@gmail.com, agossoujoseph@gmail.com, kofadier@yahoo.fr, blaise_ayivi@yahoo.fr

How to cite this paper: Noudamadjo, A., Kpanidja, G.M., Mohamed, F.A., Zinvokpodo, K.M., Ahodegnon, R., Agossou, J., Adédémy, J.D. and Ayivi, B. (2021) Neonatal Morbidity and Mortality from 2010 to 2016 in the Neonatal Care Unit of the University Teaching Hospital of Parakou/Benin. Open Journal of Pediatrics, 11, 215-224. https://doi.org/10.4236/ojped.2021.112021

Received: January 23, 2021

Accepted: May 28, 2021

Published: May 31, 2021

Copyright $\odot 2021$ by author(s) and Scientific Research Publishing Inc. This work is licensed under the Creative Commons Attribution International License (CC BY 4.0).

http://creativecommons.org/licenses/by/4.0/ (c) (i) Open Access

\begin{abstract}
Introduction: Neonatal mortality accounts for $44 \%$ of deaths among children. This study aimed to investigate neonatal morbidity and mortality in the neonatal care unit of the University Teaching Hospital of Parakou (CHU-P) from 2010 to 2016. Patients and Methods: This research was a retrospective, descriptive and analytical study that covered the period from January 1, 2010 to December 31, 2016. It focused on the medical records of newborns hospitalized in the said unit during the period mentioned above. Study variables were sociodemographic, clinical, paraclinical and outcome. Findings: During the time span of the study, 6204 newborns were registered. Sex ratio was 1.32. Mean age for newborns was $6.01 \pm 5.39$ days. Clinically obvious neonatal infection (54.1\%), prematurity and low birth weight (34.8\%) and perinatal asphyxia (30\%) were the main diseases of newborns recorded in the unit during the study period. Mortality rate was $16.8 \%$ including $77.9 \%$ occurred in the first week of life and $62.1 \%$ in the first 24 hours of life. Conclusion: More than one in six newborns died and three out of five deaths occurred in the first 24 hours of life. Therefore, it seems wise to carry out a case-control study with multivariate analysis in order to identify the main risk factors for that mortality.
\end{abstract}




\section{Keywords}

Benin, Morbibidity, Mortality, Newborns, Parakou

\section{Introduction}

Neonatal mortality accounts for $44 \%$ of deaths among under-five year children [1]. If the higher number of deaths of newborns is recorded in South Asia, the higher mortality rates are noted in Sub-Saharan Africa [2]. In Benin, according to the 4th Benin Population and Health Survey (EDSB-IV), neonatal mortality was estimated at $20 \%$ o between 2008 and 2012 for child mortality of $36 \%$ in the Borgou region [3]. In the CHU-P neonatal care unit where a similar study had already been carried out between 2002 and 2009, intra-hospital neonatal mortality was estimated at $21.1 \%$ [4]. This research work was initiated in order to measure the progression of trends in neonatal mortality within the hospital during the next seven years. Its objective was to investigate neonatal morbidity and mortality in CHU-P neonatal care unit from 2010 to 2016.

\section{Patients and Methods}

This research was a retrospective, descriptive and analytical study carried out in the neonatal care unit of the CHU-P pediatric ward in the North of Benin. It covered the period running from January 1, 2010, to December 31, 2016, i.e. seven (07) years and involved all the newborns hospitalized in the neonatal care unit during the study period. To be included, the newborns should be admitted alive during the study period with a medical bearing the diagnosis and type of discharge. The study excluded all the newborns admitted alive, dead on admission within fifteen minutes, who had no usable medical record (including neither diagnosis nor type of discharge). The cases were recruited through an exhaustive census including systematically all the medical records of patients meeting inclusion criteria. The main variables were morbidity expressed with frequencies of diagnosed diseases and then mortality expressed using death rates. The other variables were sociodemographic (mothers' age and occupation), clinical (gestational age, birth weight, neonatal morbidity), and outcome (neonatal mortality). The different diagnoses were considered as recorded in the medical records. The data were entered and processed using the software EPI INFO version 7.2. The measures of central tendency and dispersion (Mode, Median, Standard deviation) were used to describe the quantitative variables. Ratios or proportions were used to describe qualitative variables. Khi test was used to compare ratios and proportions and difference was considered as significant if p-value $<0.05$.

\section{Ethical and Professional Considerations}

The performance of this study has been authorized in writing by the CHU-P Di- 
rector; the processing of medical records has been authorized by the Head of the Pediatric Ward. Data anonymity and confidentiality were guaranteed and maintained.

\section{Findings}

\subsection{Population Description}

In the whole pediatric ward of CHU-P, 24,597 children were admitted during the study period, including 6238 newborns. Among the latter, 6224 had a medical record. Among those 6224 medical records, 20 did not get information on exclusion modalities. In total, the study focused on 6204 newborns who were live babies admitted to the unit and with usable medical records. Newborns thus accounted for $25.2 \%$ of admissions in the ward.

The mean age for mothers was $26.3 \pm 9.1$ years. Mothers aged 20 to 35 years were the predominant age group (81.1\%). Among the mothers, 3641 were housewives (58.7\%). Among all the newborns, 3530 were boys (56.9\%) and 2674 were girls (43.1\%) i.e. a sex ratio of 1.32 . Mean age for newborns on admission was $6.01 \pm 5.39$ days. The newborns admitted were aged 24 hours and younger in $73.0 \%$ of cases. Four thousand three hundred and four (4304) newborns were born in CHU-P maternity i.e. a frequency of $69.4 \%$ and 4238 (68.3\%) had a presumed date of childbirth between 37 and 41 weeks of amenorrhea. Mean birth weight of newborns was $2608.85 \pm 727.67 \mathrm{~g}$. Table 1 shows the distribution of newborns admitted from 2010 to 2016 to the CHU-P neonatal care unit according to sociodemographic, obstetrical and fetal characteristics.

\subsection{Chronological Evolution of Admissions and Deaths per Year}

We note an overall trend of increase in admissions over the years until 2013; it was followed by a decline. Figure 1 illustrates the chronological trends in admissions and deaths during the study period.

\subsection{Neonatal Morbidity}

As regards diseases and syndromes concerning all the newborns, 3357 had a clinically obvious neonatal-infection (54.1\%), 2158 were premature (34.8\%), and 1863 had perinatal asphyxia (30.0\%). Table 2 shows the distribution of newborns admitted from 2010 to 2016 to the CHU-P neonatal care unit according to diseases and syndromes.

\subsection{Overall and Annual Trends in Mortality}

Among the 6204 newborns admitted to the CHU-P neonatal care unit from 2010 to 2016,1045 died i.e. gross mortality of $16.8 \%$. Over the years, the following death rates were recorded: $18.4 \%, 21.2 \%, 21.3 \%, 13.6 \%, 13.9 \%, 16.8 \%$ and $15.1 \%$ respectively in 2010, 2011, 2012, 2013, 2014, 2015 and 2016. Table 3 indicates the trends in admissions, deaths and death rates in the CHU-P neonatal care unit from 2010 to 2016. 
Table 1. Distribution of newborns admitted from 2010 to 2016 to the CHU-P neonatal care unit according to sociodemographic, fetal and obstetrical characteristics $(\mathrm{N}=6204)$.

\begin{tabular}{|c|c|c|}
\hline & Population size & Ratios (\%) \\
\hline \multicolumn{3}{|l|}{ Mothers' age } \\
\hline$<20$ & 723 & 11.6 \\
\hline $20-35$ & 5030 & 81.1 \\
\hline$>35$ & 451 & 7.3 \\
\hline \multicolumn{3}{|l|}{ Mother's occupation } \\
\hline Housewife & 3641 & 58.7 \\
\hline Craftswoman & 1233 & 19,9 \\
\hline Civil servant & 754 & 12.2 \\
\hline High school /University student & 576 & 9.3 \\
\hline \multicolumn{3}{|l|}{ Sex } \\
\hline Male & 3530 & 56.9 \\
\hline Female & 2674 & 43.1 \\
\hline \multicolumn{3}{|l|}{ Newborns' age } \\
\hline$\leq 1$ day & 4529 & 73.0 \\
\hline 2 - 7 days & 1110 & 17.9 \\
\hline$>7$ days & 565 & 9.1 \\
\hline \multicolumn{3}{|l|}{ Place of birth } \\
\hline In Born & 4304 & 69.4 \\
\hline Out Born & 1900 & 30.6 \\
\hline \multicolumn{3}{|l|}{$\begin{array}{l}\text { Presumed date of childbirth } \\
\text { (Weeks of Amenorrhea) }\end{array}$} \\
\hline$<28$ & 120 & 1.9 \\
\hline $28-31$ & 390 & 6.3 \\
\hline $32-34$ & 598 & 9.6 \\
\hline $35-36$ & 747 & 12.1 \\
\hline $37-41$ & 4238 & 68.3 \\
\hline$>41$ & 111 & 1.8 \\
\hline \multicolumn{3}{|l|}{ Birth weight } \\
\hline Very low weight $(<1500 \mathrm{~g})$ & 492 & 7.9 \\
\hline Low weight $(1500-2499 \mathrm{~g})$ & 1724 & 27.8 \\
\hline Normal weight (2500 - $3999 \mathrm{~g})$ & 3795 & 61.1 \\
\hline Macrosomia ( $\geq 4000 \mathrm{~g})$ & 193 & 3.1 \\
\hline
\end{tabular}


Frequencies (\%)

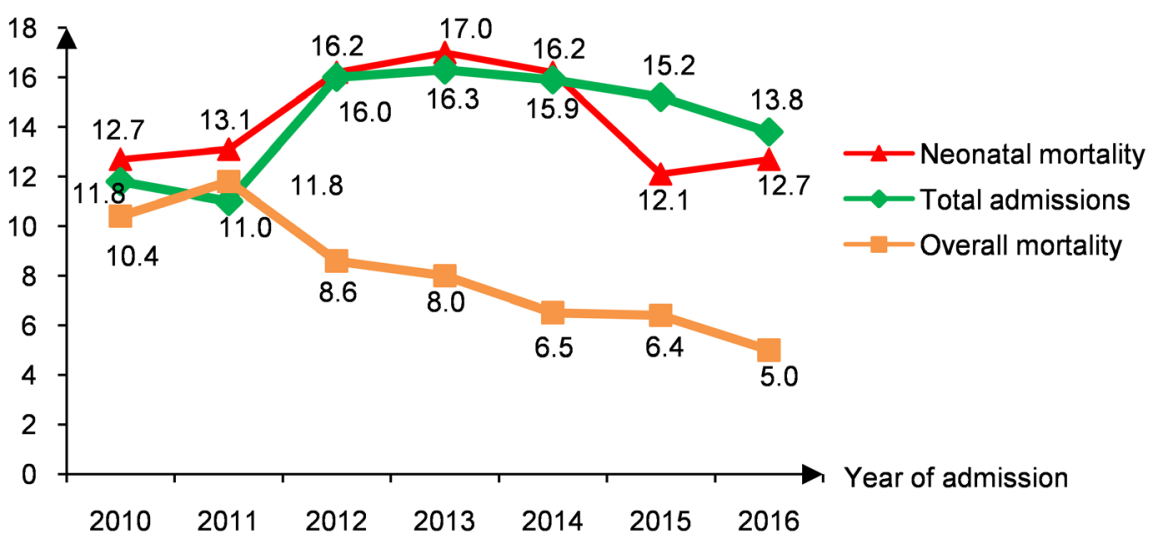

Figure 1. Evolution of annual ratios of newborn admission and deaths from 2010 to 2016 to the CHU-P neonatal care unit $(\mathrm{N}=6204)$.

Table 2. Distribution of newborns admitted from 2010 to 2016 to the CHU-P neonatal care unit according to diseases and syndromes $(\mathrm{N}=6204)$.

\begin{tabular}{ccc}
\hline & Population size & Ratios (\%) \\
\hline Obvious neonatal infection & 3357 & 54.1 \\
Prematurity and Low birth weight & 2158 & 34.8 \\
Perinatal asphyxia & 1863 & 30.0 \\
Neonatal respiratory distresses & 1412 & 22.8 \\
Pathological neonatal jaundice & 1172 & 19.0 \\
Neonatal malaria & 1053 & 17.0 \\
Neonatal hypoglycemia & 676 & 10.9 \\
Birth traumas & 396 & 6.38 \\
Congenital malformations & 358 & 5.8 \\
Other diseases & 258 & 4.16 \\
\hline
\end{tabular}

Table 3. Trends in admissions, deaths and death rates in the CHU-P neonatal care unit from 2010 to $2016(\mathrm{~N}=6204)$.

\begin{tabular}{cccc}
\hline Years & Number of admissions & Number of deaths & Mortality rates (\%) \\
\hline 2010 & 789 & 143 & 18.1 \\
2011 & 816 & 171 & 21.0 \\
2012 & 1004 & 211 & 21.0 \\
2013 & 1052 & 141 & 13.4 \\
2014 & 1008 & 138 & 13.7 \\
2015 & 748 & 124 & 16.6 \\
2016 & 787 & 117 & 14.9 \\
Total & 6204 & 1045 & 16.9 \\
\hline
\end{tabular}


Deaths occurred in $62.1 \%$ of cases in the first 24 hours of life. Figure 2 shows the distribution of newborns deaths in the unit according to their age.

\subsection{Factors Associated with Death}

As presented in the Table 4, the factors associated with neonatal death, were the mothers' age ( $<20$ years), the mothers' occupation (housewife, /craftwoman), the newborn sex (male), the newborns' age ( $>1$ day), the gestational age ( $<37$ weeks), and the birth weight $(<2500 \mathrm{~g})$.

Table 4. Factors associated with deaths in the CHU-P neonatal care unit from 2010 to $2016(\mathrm{~N}=6204)$.

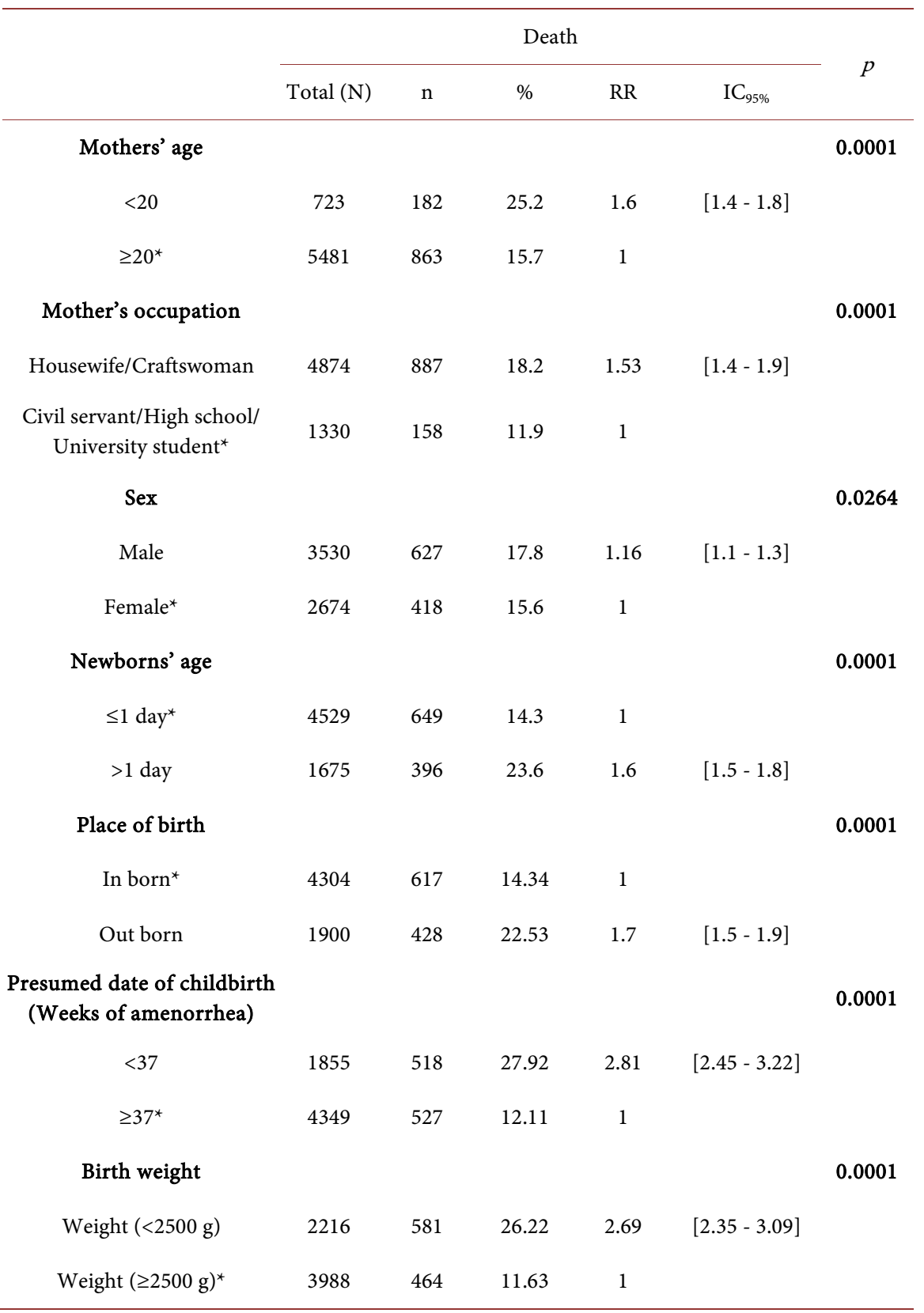

${ }^{\star}$ Reference terms. 


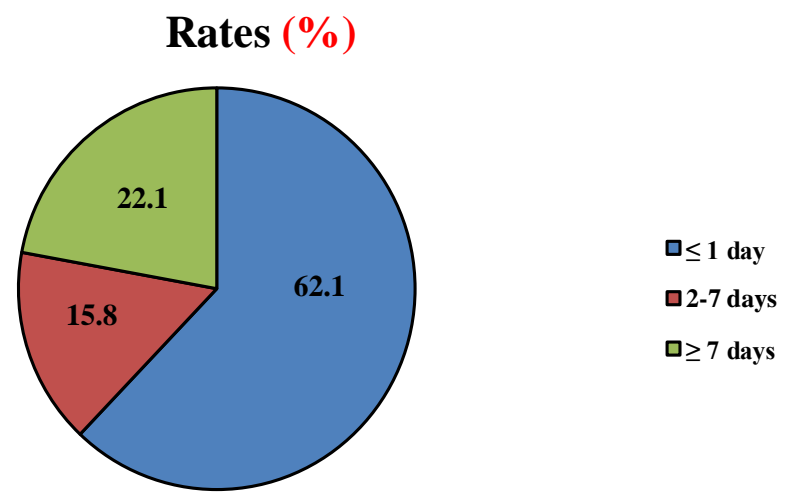

Figure 2. Distribution of newborns deaths in the CHU-P neonatal care unit from 2010 to 2016 according to their age $(\mathrm{N}=6204)$.

\section{Discussion}

This cross-sectional study based on a retrospective and analytical collection of data was carried out in the CHU-P neonatal care unit over a seven-year period. It thus has the merit of taking stock of admissions and mortality cases in the neonatal care unit since 2010. This may help make organizational and therapeutic decisions to improve the provision of care for newborns in the future. Despite its retrospective nature, source of possible missing data, it has the particular advantage of addressing a health issue in that area of the country.

\subsection{Neonatal Morbidity}

During the study period, intra-hospital-based neonatal morbidity accounted for $25.2 \%$ of general morbidity in the pediatric ward. This rate indicates the importance of neonatal care unit in that second referral ward. It points out the level of demands of neonatal care by the beneficiary population. This rate is higher than the one found out by Noudamadjo et al. in a similar study carried out from 2002 to 2009 in the same ward which was estimated at $17.8 \%$ [4]. Therefore, there is an upward trend in neonatal care needs expressed by the population.

The most common diseases were respectively neonatal infections (54.1\%), prematurity and low birth weight (34.8\%) and perinatal asphyxia (30\%). Neonatal infections were the most common disease, with $54.1 \%$ of admissions. This frequency of neonatal infections may be due either to the poor follow-up of pregnancy and lack of asepsis during childbirth or to manipulations during neonatal sepsis. For instance, in addition to classical maternal and fetal infections, the traditional practices which consist in having the umbilical cord fall down before the 72 nd hour of life, would predispose those newborns to get infections which start from the umbilical cord. These findings are identical to the ones reported by Noudamadjo et al. between 2002 and 2009 in a study conducted in the same unit which showed that $57.8 \%$ of the hospitalizations were decided for neonatal infections [4]. The predominance of neonatal infections among newborn diseases has been reported by several African authors with rates of $62 \%$ according to Kedy Koum et al. and $63.7 \%$ according to Thomson et al. 
[5] [6]. Other authors reported lower rates. Those authors were Nagalo et al. who found $23.5 \%$ and Akaffou et al. 30.3\% [7] [8]. Prematurity and low birth weights were the second cause of hospitalization. This part of prematurity in the structure of diseases raises many problems such as content and quality of care inputs ranging from health staff to consumables trough equipment. That equipment is particularly insufficient and even non-existent in our context, thus predisposing the extremely premature newborns to a very high risk for death. This result is similar to the one of Kedy Koum et al. in Douala (28.9\%), the one reported by Azoumath et al. in Togo (22.2\%), and also similar to the one reported by Bobossi in the Central African Republic (37.1\%) [5] [9] [10]. Noudamadjo et al. $(27.57 \%)$ found a rate close to the one of this study [4]. In contrast, Nagalo et al. in Burkina Faso found a lower rate (17.8\%) [7]. Perinatal asphyxia was also a common cause of admission to the unit. It was the third cause of hospitalization. For instance, $30 \%$ of admissions were decided for perinatal asphyxia. This high rate of perinatal asphyxia raises the problem of the quality of perinatal medicine in Benin. In fact, the prevention of asphyxia depends on the good follow-up of pregnancy, particularly in the last quarter, a systematic and proper actual use of the partograph in the management of labor and on good neonatal resuscitation according to the concept of Help Babies Breathe (HBB) if necessary. Nagalo et al. reported a rate lower than the one of this study (20.9\%) [7], as well as Thomson et al. in South Sudan (4.7\%) [6]. As regards Kedy Koum et al., they reported a rate close to the one of this study (27.4\%) [5], whereas Noudamadjo et al. reported a higher ratio (42\%) [4].

\subsection{Neonatal Mortality}

During the study period, the gross rate of neonatal mortality in the CHU-P was $16.8 \%$. This high rate may be due to the method of recruitment of newborns. This rate is lower than the one found by Noudamadjo et al. (21.1\%) [4]. Kouéta et al. had found a neonatal mortality rate close to the one of this study $(15.3 \%)$ [11]. Nagalo et al. in Burkina Faso (13.1\%) as well as Noria et al. in Algeria (5.3\%) reported rates lower than the one of this study [7] [12]. In the West African sub-region, in Nigeria for example, Omoigberale et al. reported in 2010 a neonatal mortality of 20.3\%; Mabiala-Babela et al. reported in 2009 in Congo neonatal mortality of $36.8 \%$ [13] [14]. The death rate has gradually declined from $21.3 \%$ to $13.6 \%$ during the seven years of the study. The two extremes were observed in 2012 with the highest death rate $(21.3 \%)$ and in 2013 with the lowest rate $(13.6 \%)$. That gradual decline of the death rate during the study may be due to the sustained and continued efforts of the medical staff to improve care provision. Actually, hygiene was improved within the unit since 2009 through the systematization of the use of disposable diapers for any newborn who was therein admitted. In addition, the training of inmate trainees and maternities' staffs in emergency obstetrical and neonatal care (EmONC) contributed to reducing that neonatal mortality rate. Within the CHU-P neonatal care unit, $77.9 \%$ of neonatal 
deaths were recorded during the first week of life. Deaths in the first 24 hours of life accounted for $62.1 \%$ of cases. This result is higher than the one reported by Noudamadjo et al. who had found $75 \%$ of neonatal mortality occurred in the first week of life and $48.3 \%$ in the first 24 hours of life [4]. Kouéta et al. in Ouagadougou in 2007, Noria et al. in Algeria in 2015 and Sylla et al. in Mali in 2009 reported neonatal mortalities in the first week of life respectively estimated at $97.3 \%, 96.85 \%$ and $91.10 \%$ [11] [12] [15]. These results give rise to many reflections. At first sight, one would think that newborns were admitted in a very precarious health condition; this raises the issue of management of pregnant women, labor, and newborns within the community before admission; each of those three components should be improved to reduce neonatal mortality. Then, despite the precarious health condition of newborns on their admission, if the installations, the medical and technical equipment, the consumables, the drugs, and staff professional skills were at a high level, a certain number of dead newborns could have recovered. This raises once again the issue of financing of neonatal care units in Sub-Saharan Africa in general and especially in Benin.

\subsection{Factors Associated with Death}

This study shows that the following factors were associated with death: the age of the mother (less than 20 years), the mother occupation (poorly paid), the male gender of the newborn, the newborns' age less than a day, the place of birth outside the reference hospital (out born), low birth weight and prematurity. These factors related to death are those described in the literature [4] [7] [9] [13] [15]. It is by acting on these factors that we can reduce the still high death rate in our unit.

\section{Conclusion}

This study points out that newborn admissions accounted for more than a quarter of admissions to the pediatric ward. The most common diseases were neonatal infection, prematurity and low birth weight and perinatal asphyxia. More than one out of six newborns died and three out of five deaths occurred in the first 24 hours of life. This high mortality suggests conducting a prospective study on the real factors associated with deaths.

\section{Conflicts of Interest}

The authors declare no conflicts of interest regarding the publication of this paper.

\section{References}

[1] Lawn, J.E., Cousens, S. and Zupan, J. (2005) Four Million Neonatal Deaths: When? Where? Why? The Lancet, 365, 891-900. https://doi.org/10.1016/S0140-6736(05)71048-5

[2] Liu, L., Oza, S., Hogan, D. and Perin, J. (2014) Global, Regional, and National 
Causes of Child Mortality in 2000-13, with Projections to Inform post-2015 Priorities: An Updated Systematic Analysis. The Lancet, 385, 430-440.

https://doi.org/10.1016/S0140-6736(14)61698-6

[3] Ministry of Development, Economic Analysis and Planning (MDAEP) and National Institute of Statistics and Economic Analysis (INSAE) (2013) 4th Population and Health Survey (EDSB-IV) Benin 2011-2012: 12, Cotonou, Beninp, 222-229.

[4] Noudamadjo, A., Agossou, J., Adédémy, J.D., Koussihouedé, C. and Ayivi, B. (2012) Neonatal Morbidity and Mortality from 2002 to 2009 in the CHD-B Neonatal Care Unit (BENIN). Annals of the University of Parakou, "SCIENCES DE LA SANTE" Series, 2, 7.

[5] Koum, K.C.D., Essomba, E.N., Ngaba, P.G., Sintat, S., Ndombo, K.P. and Coppieters, Y. (2015) Morbidity and Risk Factors for Neonatal Mortality in a Referral Hospital of Douala. The Pan African Medical Journal, 20, Article No. 258. https://doi.org/10.11604/pamj.2015.20.258.5648

[6] Thomson, J., Schaefer, M., Camino, A.B., Kahindi, D. and Hurtado, N. (2017) Improved Neonatal Mortality at a District Hospital in Aweil, South Sudan. Journal of Tropical Pediatrics, 63, 189-195. https://doi.org/10.1093/tropej/fmw071

[7] Nagalo, K., Dao, F., Housseini, F.T. and Diarra, Y. (2013) Morbidity and Mortality of Newborns Hospitalized over 10 Years at the El Fateh-Suka Clinic (Ouagadougou, Burkina Faso). The Pan African Medical Journal, 14, Article No. 153. https://doi.org/10.11604/pamj.2013.14.153.2022

[8] Adja, E.A., Dick, F.A.-T. and N'gucssan, R. (2009) Epidemiological Study of Malaria during the Neonatal Period in the Teaching Hospital of Yopougon/Republic of Côte d'Ivoire. Mali Médical, 24, 36-39.

[9] Azoumah, K.D., Balaka, B., Aboubakari, A.S., Matey, K., Yolou, A. and Agbèrè, A.R. (2010) Neonatal Morbidity and Mortality in the University Teaching Hospital (CHU) of Kara/Togo. Médecine d Afrique Noire, 57, 109-112.

[10] Bobossi, S.G., Deyamissi, T.S., Diemerh, C., Gaudueille, A., Gresenguet, G., Mandaba, J.L., et al. (2004) Neonatal Morbidity and Mortality in the Pediatric Complex of Bangui (Central African Republic). Médecine d Afrique Noire, 51, 159-153.

[11] Koueta, F., Ye, D., Dao, L., Neboua, D. and Sawadogo, A. (2007) Neonatal Morbidity and Mortality from 2002 to 2006 in the Charles de Gaulle Pediatric University Teaching Hospital of Ouagadougou (Burkina-Faso). Cahier d études et de recherches francophones/ Santé, 17, 187-191.

[12] Noria, H., Sarah, O. and Asmaa, O. (2015) Risk Factors for Neonatal Mortality in the Gynecology and Obstetrics Hospital of the Wilaya of Sidi Bel Abbes, Algeria. The Pan African Medical Journal, 20, Article No. 387. https://doi.org/10.11604/pamj.2015.20.387.5032

[13] Omoigberale, A.I., Sadoh, W.E. and Nwaneri, D.U. (2010) A 4-Year Review of Neonatal Outcome at the University of Benin Teaching Hospital, Benin City. Nigerian Journal of Clinical Practice, 13, 321-325.

[14] Mabiala-Babela, J.R., Makoumbou, P.R., Mbika-Carderoll, A., Tsiba, J.B. and Senga, P. (2009) Evolution of Hospital-Based Mortality among Children in Brazzaville (Congo). Médecine d' Afrique Noire, 56, 5-8.

[15] Sylla, A., Gueye, M., Diouf, S., Ndiaye, O., Fall, A.L., et al. (2009) Pediatric Emergencies in Dakar (Senegal). Risk Factors for Death. Médecine d' Afrique Noire, 56, 495-500. 